I Universidade de São Paulo (USP), Departamento

de Ciência Política, São Paulo, SP, Brasil

belinelli.leonardo@gmail.com

https://orcid.org/oooo-0002-4622-5366

Leonardo Octavio Belinelli de Brito'

\title{
A CRISE DO LULISMO E AS INTERPRETAÇÕES DO BRASIL
}

Singer, André. (20I8). O lulismo em crise - um quebra-cabeça do período Dilma (20 I-20I6). São Paulo: Companhia das Letras.

O lulismo em crise - um quebra-cabeça do período Dilma (20I I-20I6) é um livro complexo. Em primeiro lugar, porque se propõe analisar um período, embora curto, de forte intensidade política, como revelam os vários acontecimentos inesperados que, combinados, formaram um cenário jamais visto no período da Nova República (I989-). Ademais, junto dessa crise política, surgiu o que se poderia chamar de crise da ciência política brasileira, cujas teses então dominantes sobre o modo de funcionamento da vida política local foram radicalmente abaladas.

Essas complexidades são internalizadas na própria forma do livro, ela mesma um quebra-cabeça. Além da introdução e conclusão, o livro possui sete capítulos divididos em três partes: a parte I, composta por três capí- tulos, um excurso denominado Intermezzo histórico, e a parte II, também arquitetada em três capítulos. A simetria da estrutura das partes é, em parte, enganosa, pois não revela a urdidura complexa de seus níveis. Seu cosimento delicado, no entanto, se expõe ao leitor atento quando o autor enuncia suas quatro hipóteses, elas mesmas em níveis diversos. A primeira, denominada pelo autor "hipótese teórica geral" (p. 24), sugere que o lulismo, mesmo sem desejar confrontar o capital, acabou tocando no ponto nevrálgico da formação brasileira, a existência de uma enorme massa populacional que está aquém da exploração capitalista regular, chamada pelo autor de subproletariado. Já as demais, denominadas "hipóteses específicas" (p. 24) são as seguintes: Dil- 
ma Rousseff (PT) teria tentado acelerar o ritmo do lulismo por meio da combinação de uma guinada desenvolvimentista na política econômica com uma inflexão republicana na condução do Estado; por consequência, teria surgido o que Singer chama de "frente antidesenvolvimentista e antirrepublicana”, a qual teria sido decisiva para o impeachment da ex-presidente. Por fim, diante das dificuldades que enfrentava, Dilma Rousseff teria passado a tomar ações contraditórias. Assim, se a primeira dá continuidade à tese, por assim dizer, "estrutural" sobre a existência do subproletariado já presente em Os sentidos do lulismo (Singer, 20I2), as demais se localizam em planos mais conjunturais, eles também diversos. Por exemplo, o capítulo sete, no qual se analisam as movimentações dos atores na batalha do impedimento, tem algo de thriller político.

Vistas as hipóteses, é possível presumir que, por uma série de razões compreensíveis, o livro deverá ser lido como uma tentativa de explicar o impeachment da ex-presidente Rousseff, a despeito da intenção do autor (p. 3233). O que talvez fique em segundo plano nessa leitura, entretanto, é a forma pela qual Singer busca explicá-lo, ${ }^{\mathrm{I}}$ qual seja: a inscrição dos impasses contemporâneos da política brasileira em um quadro mais amplo e complexo da formação social do país. E é dela, a nosso ver, que advém toda a força do livro. É para esse elemento que essa resenha deseja chamar a atenção.

Em linhas gerais, Singer formula a tese segundo a qual o golpe parlamentar de 2016 seria uma resposta à re- configuração do cenário político brasileiro pós-realinhamento eleitoral ocorrido em 2006, tal como argumentado em Os sentidos do lulismo. Por quê? Porque o lulismo, a despeito de ser um "reformismo fraco" com dimensões "progressivas e regressivas", teria tocado naquilo que o autor chama de "principal contradição brasileira", a reprodução permanente da "sobrepopulação trabalhadora superempobrecida permanente" (Singer, 20I2: I8), o subproletariado. Ao trazer essa questão à tona, Singer argumenta que esse cenário político complexo só pode ser entendido se tivermos em mente as especificidades do capitalismo periférico brasileiro e das relações de classe por ele engendradas. É essa questão que vincula seu livro aos conceitos e questões formulados pelos chamados intérpretes do Brasil.

Por exemplo, a hipótese da existência do subproletariado é vinculada à percepção de Caio Prado Júnior, segundo a qual existe uma forma especialmente perversa de inserção dos muitos pobres na sociedade brasileira, cuja função é não ter função. Daí que o autor os designe como "setor inorgânico" (p. I8). Retomada pela Escola de Sociologia Paulista, essa análise ganhará novos contornos com a descoberta, por parte de Maria Sylvia de Carvalho Franco (I 997), do favor como a mediação ideológica que rege a busca pela inserção desses setores na sociabilidade brasileira. Esse tema aparece no livro a partir da referência à obra de Roberto Schwarz (20I2), analista dos desmandos das classes dominantes brasileiras figurados nos 
romances de Machado de Assis. É por meio da incorporação desses clássicos que Singer percebe, portanto, as especificidades das relações de classes no país, elemento sem o qual não se explica o programa do lulismo, baseado na busca de reformas sociais sem confrontação com a ordem, o que se deve à profunda vulnerabilidade que o subproletariado possui diante de quaisquer movimentos bruscos da sociedade brasileira. Daí sua dificuldade de se colocar, de forma autonomamente organizada, na cena política como classe. As dívidas de Singer com a interpretação do populismo de Francisco Weffort (I978), que formulou a tese sobre a relação complexa entre "classes" populares e "massas" no país, aqui são evidenciadas. Importa destacar que a crítica de ambos se dirige, como em outros intérpretes do país, às estruturas de dominação que impedem a articulação política e social dos setores populares, que se tornam dependentes de direções "do alto" - as quais, em parte, atendem a seus anseios.

Em estreita conjugação com o processo de formação das classes sociais brasileiras, há também a retomada de estudos clássicos locais que analisam a dinâmica perversa do processo de modernização de nosso capitalismo. Aqui, tem centralidade o trabalho de Francisco de Oliveira (20I I), que percebeu como a vulnerabilidade dos setores populares foi especialmente funcional para o processo de aprofundamento das relações capitalistas no Brasil do século XX. Ou seja: a não integração, vista como resíduo do nosso "atraso", é funcional para a nossa modernização porque elimina um dos polos que pode moderar/bloquear a exploração. "Existe a sensação intuitiva, mas falsa, de que o atraso segura, suga para baixo o setor moderno, quando é o oposto [...]. A realidade é contraintuitiva: o limbo funciona como a atmosfera da qual o moderno retirar o ar que respira - ou melhor, a mão de obra que o alimenta." (p. 22). É precisamente esse raciocínio que estrutura a principal novidade do livro, presente no Intermezzo histórico, e sintomaticamente deixada de lado pela análise de Rocha de Barros (20 I8). Que novidade é essa? É a tese de que a democracia brasileira sofre de um desequilíbrio estrutural. Ao estudar as raízes sociais do sistema partidário brasileiro, Singer percebe que, desde as incorporações das massas na política institucional, o sistema tende a se realinhar de modo que os principais partidos sejam apoiados pelos setores populares (PTB/MDB/PT), médios (UDN/Arena/PSDB) e por aqueles que se vinculam à política por meio da lógica clientelista (PSD/Arena/ PMDB) - política de "segundo grau", segundo Singer, reconhecidamente inspirado na noção schwarziana de "ideologia de segundo grau" (Schwarz, 20I2: I8-I9). Ora, se o sistema atinge seu alinhamento pleno, os partidos da classe média e do "interior" tendem a ter grandes dificuldades de vencer os pleitos, especialmente os nacionais, pois são minoritários diante das enormes massas de pobres e muito pobres da sociedade brasileira. Daí a tentação golpista que os acomete de tempos em tempos (p. I58). 
Assim, embora desiguais entre si, como o próprio autor reconhece, as partes I e II podem ser lidas como análises, de fôlegos diversos, figuradoras das nuanças das ações de sujeitos e partidos, movidos por seus interesses, profundamente vinculados à estrutura social e política identificada na análise. Estamos longe, é certo, dos tipos de análise em que a dimensão conjuntural apenas reflete as estruturas sobre as quais supostamente se assentaria. Antes o contrário: ao destacar a centralidade da política - e os "erros" da ex-presidente Dilma Rousseff, por exemplo - na conformação do lulismo, Singer aponta que a ação faz a diferença. Aqui, o mote de Marx (2008: I5), segundo o qual os "homens fazem sua própria história, mas não a fazem segundo a sua livre vontade; não a fazem sob circunstâncias de sua escolha e sim sob aquelas com que se defrontam diretamente, legadas e transmitidas pelo passado", ganha plena significância analítica. À manei- vez tenha faltado ao livro um diagnóstico mais claro sobre a situação do capitalismo global, tecido decisivo no qual se inserem os conflitos sociais e políticos brasileiros contemporâneos.

Como se vê, a reflexão de Singer exemplifica à perfeição o argumento de Élide Rugai Bastos (2002: I84), para quem "o diálogo entre as diferentes interpretações [do Brasil] é componente fundamental da busca de explicação sobe o Brasil". Isso porque, como observou Gildo Marçal Brandão (2007: 25), os nossos clássicos "continuam [a] ser lidos como testemunhas do passado e como fontes de problemas, conceitos, hipóteses e argumentos para a investigação científica do presente". É que, como nos mostra Singer, pode até mesmo ser que, com exceções entre as quais se localiza o lulismo, o desenvolvimento tenha ocorrido para não mudar os aspectos es senciais das condições de reprodução da sociedade brasileira.

Compreender como isso é possível é tarefa decisiva do cientista social brasileiro consequente com a matéria iníqua sobre a qual se debruça. Nos momentos em que ela revela sua brutalidade, algo parece acontecer na inteligência brasileira; "tudo se passa como se o esforço de 'pensar o pensamento' se acendesse nos momentos em que nossa má formação fica mais clara e a nação e sua intelectualidade se veem constrangidas a refazer espiritualmente o caminho percorrido antes de embarcar em uma nova aventura - para declinar ou submergir em seguida" (Brandão, 2007: 28). 


\section{NOTA}

I Exemplo disso é a resenha publicada por Celso Rocha de Barros (2018) no número I 2 da revista Quatro cinco um.

\section{REFERÊNCIAS BIBLIOGRÁFICAS}

Barros, Celso Rocha de. (2018). Os ensaios de Dilma. Quatro cinco um, ano 2, I2, p. 8-9.

Bastos, Élide Rugai. (2002). Pensamento social na Escola Sociológica Paulista. In: Miceli, Sérgio (org.). O que ler na ciência social brasileira 1970-2002 (v. IV). São Paulo: Editora Sumaré, p. I83-224.

Brandão, Gildo Marçal. (2007). Linhagens do pensamento político brasileiro. São Paulo: Hucitec.
Franco, Maria Sylvia Carvalho. (I997). Homens liures na ordem escravocrata. São Paulo: Unesp.

Marx, Karl. (2008). O dezoito brumário de Louis Bonaparte. São Paulo: Centauro.

Oliveira, Francisco de. (20II). Crítica à razão dualista/O ornitorrinco. São Paulo: Boitempo Editorial.

Schwarz, Roberto. (20I2). Ao vencedor as batatas. São Paulo: Editora 34/Duas Cidades.

Singer, André. (2012). Os sentidos do lulismo - reforma gradual e pacto conservador. São Paulo: Companhia das Letras.

Weffort, Francisco. (1978). O populismo na política brasileira. Rio de Janeiro: Paz e Terra.

Leonardo Octavio Belinelli de Brito é doutorando em Ciência Política pela Universidade de São Paulo (USP). Seus temas de pesquisa estão vinculados ao campo do pensamento político e social brasileiro. É autor de Dilemas do patrimonialismo brasileiro - as interpretações de Raymundo Faoro e Simon Schwartzman (Alameda, 2019) e de "Raymundo Faoro e as linhagens do pensamento político brasileiro” (2018). 